French surgeons of the early part of the last century for its recognition, and also for the term by which it is generally known, "reduction en bloc" or "en masse." Luke, in this country, first described it in the Traneactions of the Medico-Chirurgical Society, vol. xxvi, p. 159. Examination will show that the inguinal region and the rings are free, but a lump will be felt behind the abdominal wall. It has only been recorded in connexion with old inguinal herniae. In the reduction the hernia would have disappeared without the characteristic gurgle, and symptoms of obstruction would remain. Instances of it are rare, and the following case, which was under my care in St. Thomas's Hospital, is a good example :

C. C., aged 52, had been ruptured for ten years, for which he had worn a double truss. This latterly had not been satisfactory, failing to keep up the tumour. On November 19th such happened, and he was unable to reduce his hernia; he such happened, and he was unable to reduce his hernia; he tried to do so himself for two hours, but being unsuccessful he sent for his doctor, who after some three hours came in reduced the hernia. Soon after there was pain, followed by nausea, and then he vomited on three occasions in the evening. I was called to see him on the next mid-day (20th); he had then bilious vomiting, with a dry, brown tongue. His pulse was 88 , a little tense, but this was possibly due to arterial degeneration. His belly was soft, and the inguinal canal was empty of any hernial tumonr, but there was inguinal canal was empty of any hernial tumonr, but there was abdominal wall, about the brim of the pelvis, could be felt a lump, but nothing abnormal could be detected per rectum His testis was normally placed, and he was certain that he had tíad no hernia in early life. An operation was done immediately. On slitting the external oblique the tissues of the cord were greyish, with some blood extravasation and some oedema. The connective tissue over the front of the cord as well was loosened and lacersted, and no sac could be seen. On pulling on this loose subperitoneal tissue a rounded dark pulling on this loose subperitoneal tissue a rounded dark swelling came ap from the margin of the pelvis. This was the
displaced sac containing the strangulated bowel. This was opened up, and blood-stained fluid and recent fibrin were set free. The loop of bowel was dark, of good polish, and appeared to have been especially nipped over the free margin as occurs in a Richter's hernia, and the explanstion of this was forthcoming when the sac was further examined. This had a small orifice, just taking the little finger with a squeeze (threeeighths of an inch), in which the small portion of the bowel's lumen had become wedged. The size of the sac distally to this was not more than a pigeon's egg; centrally to the con-stricted opening was a well-marked peritoneal pouch, with a wide opening into the cavity. It is probable that this constriction represented the original internal ring, which bad been gradually displaced downwards. There was no omentum in the sac, and the portion of the bowel involved was the ileum. A Bassini's operation was done, and the after-progress calls for no comment except for the supervention of a haematoms of the cord, which was probably related with the bruised state of the connective tissue seen at the operation.

Reduction en masse may also take place between the planes of the abdominal muscles.

There remains for our consideration another very interesting condition, where obstruction persists after reduction, namely, when there is a bilocular sac, and the intestine is simply forced from its sac in the inguinal region into one occupying a posterior position, the lower sac not being displaced as in reduction en masse. The second pouch will be distally placed to the site of the constriction, which is usually at the internal ring, but it may be placed between the layers of the abdominal wall, forming the interparietal form of interstitial hernia.; or behind the abdominal wall in the subperitoneal tissue, when it is termed "properitoneal." The clinical history in this last form is practically the same as with a reduction en masse, and differentiation only takes place at the operation.

A very marked example of a properitoneal hernia was described by $m e$ in the Transactions of the MedicoChirurgical Society, vol. Ixxxvii, to which paper I would refer you for further details.

Before concluding this subject, there is a condition we must consider which may ensue after the best regulated taxis, or even after the return of the bowel by operation. The longer the strangulation the greater is the probability of its occurrence, and so its possibility should be another deterrent to performing taxis beyond the limits previously laid down. When a loop of bowel has been considerably altered by pressure it must be borne in mind that normal peristalsis may' not be re-established, and symptoms of obstruction will persist. The signs indicating this intestinal paresis will be progressive distension of the bowel with gas, without any passage of flatus per anum; nausea succeeded by vomiting, or vomiting itself, will persist from the first. The pulse will be weak and rather quick, but in the early stage there will be no marked alteration in temperature or in rate of respiration. If this complication is not soon relieved the vomiting will be persistent, and the bilious-coloured fluid, becoming progressively darker, will be towards the end literally pumped up. Symptoms of collapse will become more marked, the pulse will increase in rate but decrease in force, the temperature will rise, and the respirations will be more rapid, owing to the increasing pressure on the diaphragm from the distended intestines. As these symptoms may take a very few hours to run their course, it is most important to recognize the condition promptly, and to act accordingly. The great point is not to be misled with the idea that the signs are due to some temporary peritoneal inflammation. Distinguishing features between the two are that in the paretic state the signs continue after reduction, the pulse has not the wiry character nor is there the pain, increased temperature, local tenderness, or rigidity which we might expect in peritonitis. It will also be noticed that although the bowels are distended there is an absence of visible peristalsis, such as would be observed with distension of the bowel on the proximal side of a hand.

\section{FRACTURE OF THE FIFTH METATARSAL BONE.}

BY GEO. H. GRAHAM, M.D.

MEDICAL OFFICER IN CHARGE OF THE ELECTRICAL DEPARTMENT, EAST LONDON HOSPITAL FOR CHILDREN, SHADWELI, E.

Fractures of the metatarsal bones due to causes other than direct violence are sufficiently uncommon to justify recording when a case presents itself. Direct violence is usually the cause of these fractures, and frequently involves severe damage to the soft parts, when the surgical consequences may be serious. If the fracture so caused is simple, and is recognized, the injury is of little importance if proper treatment be adopted. But when no violence has been received, and there seems little or even no cause for a fracture, the injury, being unsuspected, is liable to be overlooked, and the patient, instead of keeping at rest, walks about, partially disabled, suffering much pain for a long period. Such cases, according to von Bergmann, may ultimately cause permanent partial disablement.

A clergyman, about 50 years of age, whom I bad attended for some years, consulted me on September 29th, 1906, for pain on the outer side of the right foot. He informed me that on August 10th, while walking on a gravel path and wearing Augun shöes he felt a sudden pain after he had been walking ordinary shoes, he felt a sudden pain after he had not twisted the foot, nor been jumping. Shortly afterwards he seemed to feel foot, nor been jumping. Shortly afterwards he seemed to feel pain increased greatly in severity, and he reached home with difficulty. He was treated with lotions and partial rest under medical advice. Two or three days after the injury he had a slight attack of gout in the great toe of the same foot, but this soon passed off. He experienced no relief from the pain on walking till about five weeks later, when he bound his foot round with plaster.

I found orer the base of the fifth metatarsal a distinct enlargement when compared with the other foot somewhat painful on pressure, but hard and obviously bony. No crepitus could be felt. 'An $x$-ray screen examination disclosed a trans verse fracture of the tubercular eminence at the base of th fifth metatarsal. The skiagraph showed marked separation of the fragment, with little or no attempt at bone union. On closer examination, after the $x$ rays had shown the nature of the injurs a very glight transverse groove could be made on the injury, a very slight than

The cause for such a fracture occurring without any violence in an apparently healthy man while simply walking is not very in an apparently healthy man while simply walking is not very
clear. The patient had never previously broken a bone; he clear. The patient had never previously broken a bone; he
showed no evidence of tabes or any other nerve lesion. Myeloid changes were as far as possible excluded by an examination of the urine. Mr. Eastes reported on a specimen that it "contained a most minute trace of serum albumen, but none of the tests employed showed the presence of albumose." In the absence of any inversion of the foot or any undue strain, it is difficult to believe that the action of a comparatively weak muscle, such as the peroneus brevis, would be sufficient to cause such a fracture.

The literature on the subject, as far as I have been able to discover, is very limited, the large majority of authorities briefly dismissing it with the remark that such fractures are due to direct, violence. Tobold; ${ }^{1}$ however, 
reports many cases in soldiers from prolonged marches, jumping, etc. Von Bergmann ${ }^{2}$ agrees that the condition is one more frequently met with in soldiers, and considers that the heavy knapsack they carry bas some bearing in this connexion. He mentions that in more than 90 per cent. of the cases reported the break was in the middle of the second and third metatarsal, and never in the first. He further states that with the $x$-rays Schulte, Stechow, and Kirchner found that what Breithaupt described as "tumour of the foot" was due to the fracture of a metatarsal bone (the majority being incomplete greenstick fractures), produced generally by slight violence and usually overlooked at first owing to the slight disturbance occasinned.

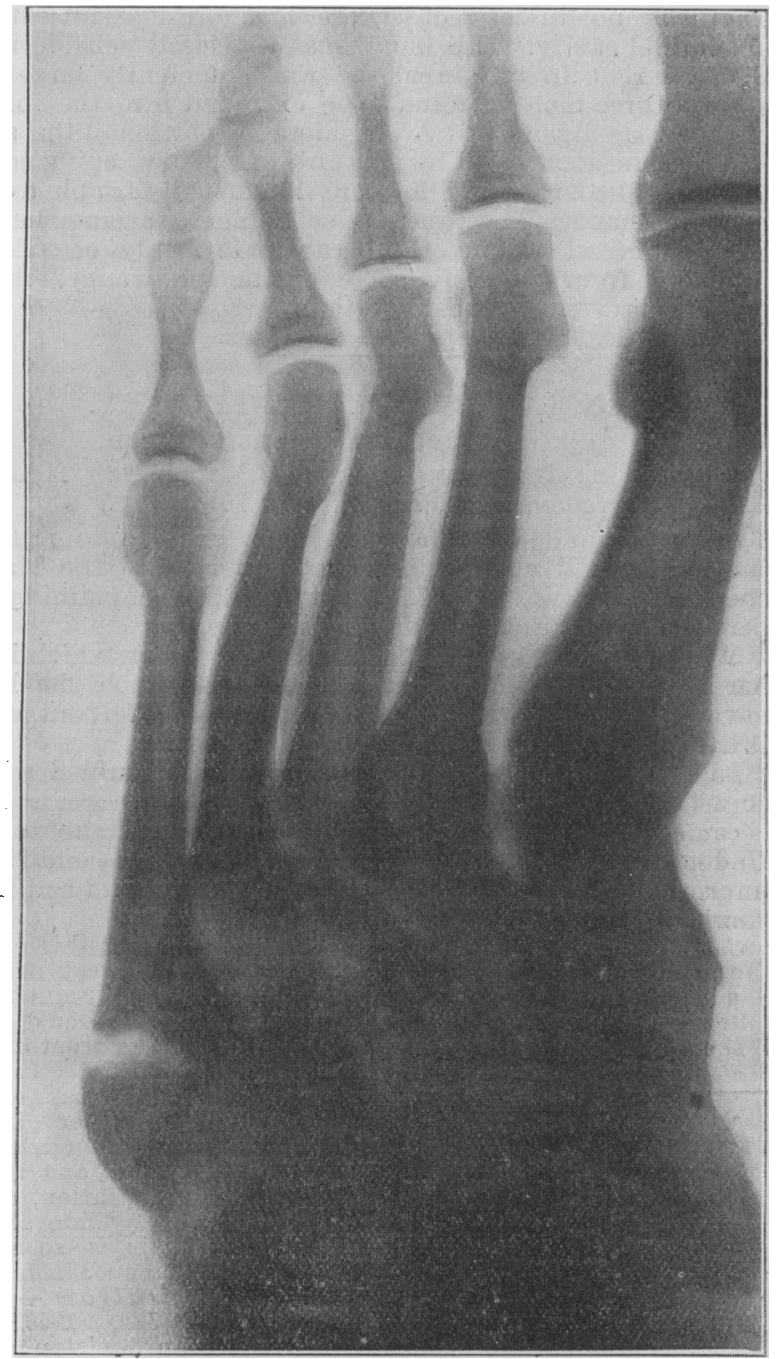

Robert Jones ${ }^{3}$ reported the fracture of his own fifth metatarsal near. the base while dancing, and four other cases from some slight indirect violence. In all these cases, as shown by the skiagraphs published, the fracture is anterior to the base, some being nearly in the centre of the shaft. He explains the fractures in his cases thus :

When the beel is off the ground the body weight expend itself upon the : fifth metatarsal, rotating it slightly inward. The opposition to this force takes place at its base, where the strongly attached ligaments resist its displacement. strongly attached ligaments resist its displacement. A fracture occurs, therefore, exactly wh
[that is, unteriorly to the base].

It will be observed that in the case now reported the fracture involves the articulation with the cuboid, and has broken off only the tubercular eminence, where it should seem there should be little or no strain, with no inversion of the foot occurring at the time. Jones lays stress on the difficulty in diagnosis of these cases without $x$ rays, as crepitus is in the majority of them unobtainable.

Whitman ${ }^{4}$ alone among the authorities I have consulted states that the injury may occur without apparent cause other than walking, and that the pain and swelling may be inexplicable without $x$ rays, but he gives no instances nor any explanation for a fracture thus occurring.

REFGRENCES.

1 Tobold, Deuilsche militaeraerztl. Zeitschrift, 1903. [Part A. Abst. in Centralblatt ,iir Chir. 1904, p. 43 . 2 Von Bergmanu, System of Practical
Surgery, vol. iii. 3 Jones, Annals of Surgery, 1902 (June). \& Whitman Orthopuedic Surgery, 1904.

\section{E M O R A N D A \\ MEDICAL, SURGICAL, OBSTETRICAL. \\ FILARIA IN BIRDS.}

With reference to the notes by Professor St. Clair Symmers and Dr. A. C. Coles in the British Medical JoURNAL of October 20th and November 3rd on the occurrence of filariae in blackbirds, it may be of interest to say that I have found filariae in the blood of at least half a dozen jungle crows (Corvus macrorhynchus) in this place.

These filariae swarm in the blood, as many as ten being often seen in one tield, under a $\frac{1}{6}$ power, while the crows containing them seem to be in perfect health. They resemble those described by Professor Symmers. They are devoid of sheath, with a smooth, structureless cuticle. The ends are blunt-one so blunt as to be almost square, the other slightly more pointed. On staining they are seen to be full of granules, with a clear space about onethird of the length from the sharper end.

I have not measured their length, but in breadth they are rather less than the shorter diameter of the red cells. in Halteridia were also present in two of the crows.

Dehra Doon, India. $\quad \begin{gathered}\text { F. WYviLLE THoMsoN } \\ \text { Lieutenant-Colonel, I.M.S. }\end{gathered}$

\section{A CASE OF BULLET WOUND.}

A YounG coloured woman, aged 19 years, was accidentally shot by a man who was standing within two yards of her with a loaded revolver. The bullet entered the left ala nasi about three-quarters of an inch from its free margin and at its junction with the cheek, and emerged isalf an inch in front of and a little above the right external auditory meatus. When seen by me, within an hour of the accident there was profuse bleeding from the wound of exit and from the pharynx. I administered a full dose of opium and $15 \mathrm{gr}$. of Burroughs, Wellcome and Co.'s suprarenal tabloids. Four hours afterwards all bleeding had ceased, and the girl was quite comfortable. Two days after the injury the right eye became considerably suffused, and there was profüse lachrymation. This condition, however, disappeared after a few days, as did also some air crepitus in the right cheek over the antrum. There was but slight shock and never any fever, and the girl was to all intents and purposes well in a fortnight.

The case seems remarkable on account of the apparently light injury inflicted by a fairly large and heavy bullet (0.38 calibre) in traversing such an important region.

Richmond, Jamaica.

P. O. Malabre, M.B., C.M.Edin,

\section{PYTHOGENIC PNEUMONIA.}

THE following instance of so-called "pythogenic pneumonia," which recently occurred in my practice, appears worth recording.

On October 1st, 1906, I saw Mrs. D., aged 28. She was suffering from severe catarrhal sore throat presenting all the appearances of the ordinary "hospital sore throat," and her temperature was $104^{\circ} \mathrm{F}$. Rain had fallen heavily on that day after a long spell of dry weather; I learnt that the water supply to the house had given out some days previously, and that the closets had not been flushed for three days. The next day Mr. D., aged 30, was in bed with a temperature of $102^{\circ} \mathrm{F}$., and all the symptoms of pneumonia. On the following day a large consolidated patch corresponding to the lower-lobe of the right lung could be distinctly made out. The course of his attack was uneventful, the temperature falling gradually and remaining below $99^{\circ} \mathrm{F}$. after the ninth day.

In the meantime Mrs. D's throat had got well, and she had helped to nurse her husband until October 20th, when she also was attacked with pneumonia at the base of the right lung, her temperature rising rapidiy to $105^{\circ} \mathrm{F}$. on October $22 n d$. On October 26 th the left lung became 